\title{
Vaccine Contents
}

\author{
Aşı Içeriği
}

Source: https://asi.saglik.gov.tr/genel-bilgiler/36-asi-icerikleri.html

Vaccines are highly reliable biological products. They are under strict control in production and distribution stages. All vaccines used in our country are vaccines licensed by globally recognized authorities such as World Health Organization, EMA and FDA or TiTCK and produced in accordance with the terms of GMP (Good Manufacturing Procedures) approved and recommended by World Health Organization. For each series produced, detailed analysis and tests are carried out by the manufacturer and the official authorities of the country in which the product is produced. Harmlessness and effectiveness analysis and compliance tests ofthe purchased vaccines and anti-serums are conducted with experienced personnel and advanced equipment by Pharmaceutical Biological and Medical Devices Laboratory of the national reference laboratory in the control of the Institute of Turkey Pharmaceutical Biological and Medical Products within the body of our Ministry of Health. All vaccines and anti-serums applied have been analyzed and are reliable. Unanalyzed vaccines are returned and new vaccinations are required in another batch.

Vaccines are kept in the appropriate temperature range in the cold chain system in all health institutions until they are taken from the manufacturer and applied to the person to be vaccinated and the system is continuously monitored with ATS.

Vaccines include substances that promote immunity and are called antigens, with small amounts of substances that are involved in making the vaccine safe and effective. Vaccines also contain adjuvants, stabilizers and preservatives alongside the Antigen. The vaccines provided by our Ministry do not contain pork products.
Adjuvant so-called additional substances are used in addition to bacteria and virus components to increase the effectiveness of vaccines. Stabilizers are substances added to the vaccine vials to maintain stability until vaccines are administered. In addition, additional agents called preservatives to prevent microbiological contamination are added to the vaccine vials. In general, our vaccines include aluminum Hydroxide as adjuvant; thiomersal with antibiotics such as (neomycin), kanamycin, erythromycin as preservative and magnesium chloride as stabilizer.

Aluminum hydroxide is used as an adjuvant to increase the effects of vaccines at very low doses, and the total amount of aluminum in all of the vaccines applied to a patient throughout his/her life is $4.25 \mathrm{mg}$. It is at a very low level determined by WHO and not harmful to human health. Td, which we apply, is included in some vaccines such as 5-combined, 4-combined, and KPA. Aluminum is abundant in drinking water, ready waters, flour and flour products, medicines, especially stomach medicines (20-30 mg) and fruit- vegetables.

Thiomersal is an organic compound of ethyl mercury and has been used as a preservative in many vaccines and drugs since the 1930s.

According to the report of the World Health Organization General Committee on Vaccine Safety (GACVS) issued on June 20 21,2002 , the half-life of ethyl mercury (thiomersal) in the body is less than one week and is removed from the body through the digestive system in 4-9 days averagely and therefore; there is no accumulation in the body such as other mercury com- 
Table 1. Ingredients in vaccines

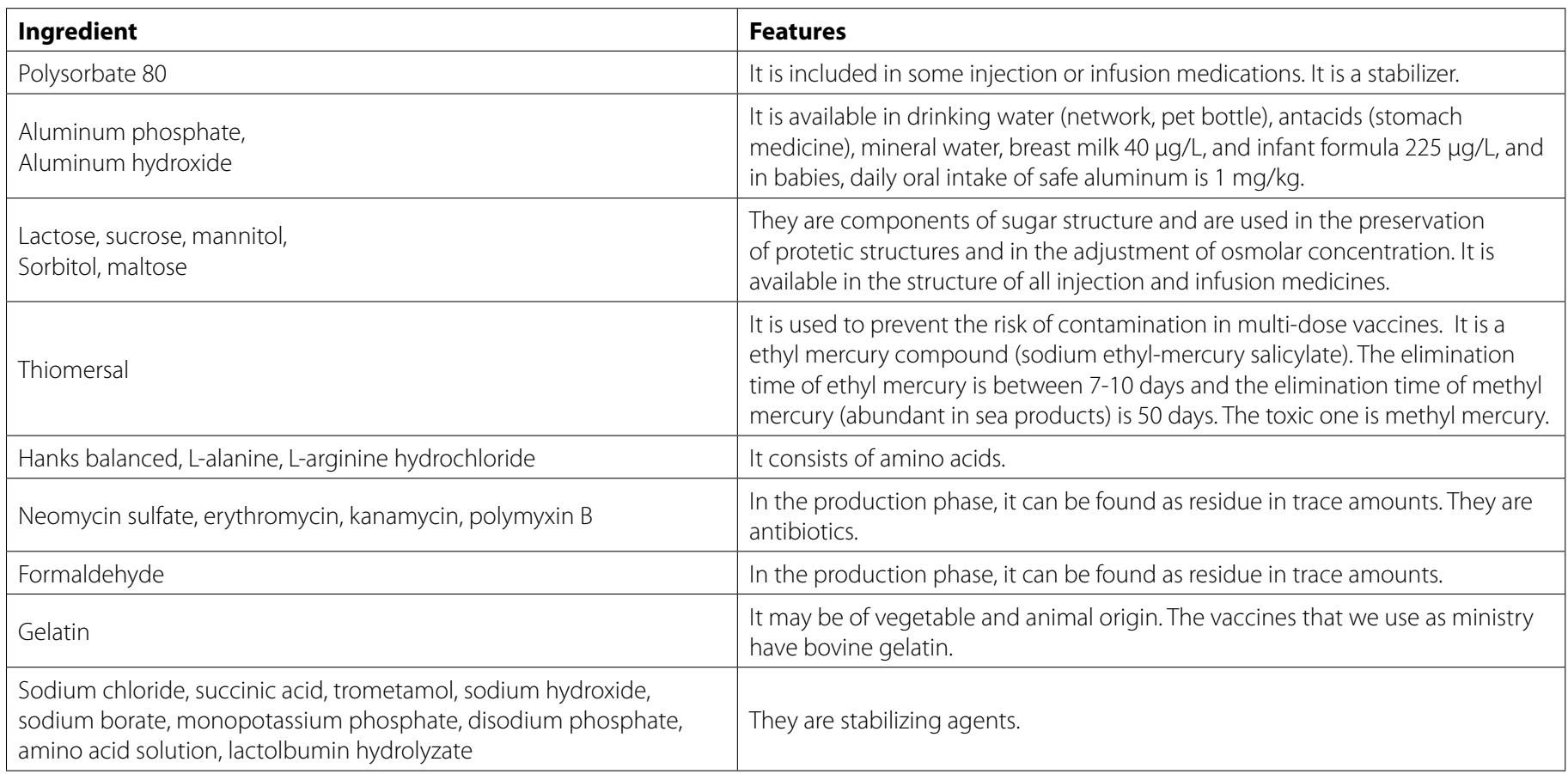

Table 2. Vaccine components quantity

\begin{tabular}{|l|c|c|c|}
\hline & Name & Quantity & Reference values \\
\hline & Aluminum & $0.25 \mathrm{mg} / \mathrm{mL}$ & $0.20-0.45 \mathrm{mg} / \mathrm{mL}$ \\
\hline Five-combination & Sucrose & $42.6 \mathrm{mg}$ & $31.9-53.1 \mathrm{mg}$ \\
\hline KPA & Formaldehyde & $10.30 \mu \mathrm{g} / \mathrm{mL}$ & $4-15 \mu \mathrm{g} / \mathrm{mL}$ \\
\hline Four-combination & Aluminum & $0.25 \mathrm{mg} / \mathrm{mL}$ & $0.2-0.3 \mathrm{mg} / \mathrm{mL}$ \\
\hline & Aluminum & $0.32 \mathrm{mg} / \mathrm{mL}$ & $0.20-0.45 \mathrm{mg} / \mathrm{mL}$ \\
\hline Hepatitis B & Formaldehyde & $9.33 \mathrm{mg} / \mathrm{mL}$ & $4-15 \mathrm{mg} / \mathrm{mL}$ \\
\hline & Aluminum & $0.60 \mathrm{mg}$ & $<1.25$ \\
\hline Td & Thiomersal & $0.0097 \% \mathrm{~W} / \mathrm{V}$ & $0.0115 \% \mathrm{~W} / \mathrm{V}$ \\
\hline & Thiomersal & $0.034 \mathrm{mg} / 0.5 \mathrm{~mL}$ & $<0.05 \mathrm{mg} / 0.5 \mathrm{~mL}$ \\
\hline Rabies & Formaldehyde & $0.0019 \mathrm{~g} / \mathrm{L}$ & $\leq 0.2 \mathrm{~g} / \mathrm{L}$ \\
\hline Hepatitis A & Thiomersal & $68.7 \mu \mathrm{g} / \mathrm{vial}$ & $0.43 \mathrm{mg} / \mathrm{mL}$ \\
\hline
\end{tabular}

pounds and it does not lead to a number of chronic diseases due to mercury. Methyl civa, which is difficult to remove from the body, is not included in thiomersal content.

Several scientific studies have been conducted to investigate the relationship between the use of thiomersal-containing vaccines and the rise of a number of chronic diseases, particu- larly autism. As a result of these studies, no relation was found between thiomersal and autism.

In light of the detailed studies conducted by the WHO General Committee on Vaccine Safety (GACVS); The European Medicines Agency (EMEA)- Patented Medical Products Board (CPMP) has declared in its study dated MArch, 2004 that there is no 
correlation between immunization with thiomersal-containing vaccines and specific neurological developmental disorders.

In the report dated 2004 of American Independent Civil National Academy of Sciences (NAS) - Institute of Medicines (IOM), it has been reported that there is no link between autism and vaccines containing measles or thiomersal as preservative, and that it is purely coincidental. Also, Harvey V. Fineberg president of the Institute of Pharmaceuticals (IOM) has once again declared that there is no relationship between Thiomersal and autism in an interview featured on NBC on August 7, 2005. In European countries and many other countries, Thiomersal is still used as a preservative in vaccines.
The WHO Global Consultative Committee on Vaccine Safety (GACVS) has also declared that the measles vaccine has no association with SSPE and autism. In this regard, the article published in Lancet has been removed and the author has been ostracized from the profession.

Several long-term studies have not shown a proven side effect of thiomersal use in the vaccine dose. Thiomersal is usually present in multi-dose vaccines and is not generally included in single dose vaccines. 